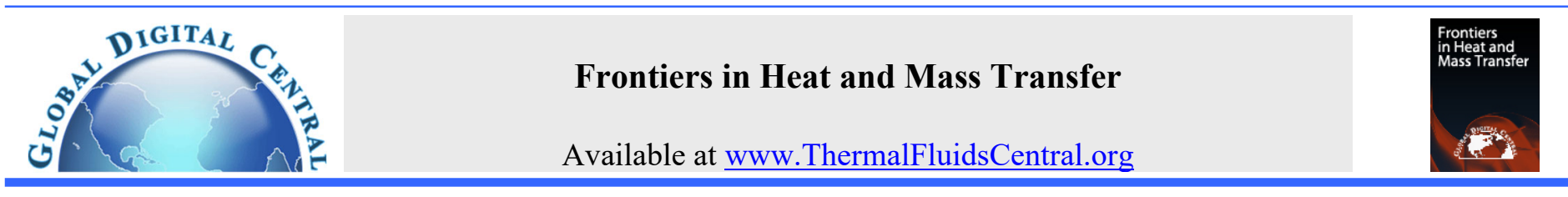

\title{
NATURAL CONVECTION IN A PARTIALLY HEATED PARALLELOGRAMMICAL CAVITY WITH V-SHAPED BAFFLE AND FILLED WITH VARIOUS NANOFLUIDS
}

\author{
Zainab Kareem Ghoben ${ }^{\mathrm{a},}{ }^{*} \dagger$, Ahmed Kadhim Hussein ${ }^{\mathrm{b}}$ \\ ${ }^{a}$ Ministry of Agriculture, Planning Department, Al-Diwaniya, Iraq \\ ${ }^{b}$ College of Engineering, Mechanical Engineering Department, University of Babylon, Babylon, Iraq
}

\begin{abstract}
The numerical analysis of a V-shaped baffle effect on the natural convection inside a parallelogrammical cavity filled with two different water-based nanofluids $\left(\mathrm{Al}_{2} \mathrm{O}_{3}\right.$ and $\left.\mathrm{Cu}\right)$ were studied in this work. The enclosure walls were maintained at a constant hot and cold temperatures on the left and right walls sequentially. The horizontal walls were isolated, while the baffles located on the right wall and sharing the same cold temperature with it. The finite element method was used to derive and solve the governing equations. The flow and thermal fields computed for different arrangements of: the number of baffles inside the cavity which were ranged as $(1,2,3)$, length and position ranged as $\left(0.25 \mathrm{~L} \leqslant l_{b} \leqslant 0.75 \mathrm{~L}\right)$ and $\left(0.25 \mathrm{~L} \leqslant h_{b} \leqslant 0.75 \mathrm{~L}\right)$, respectively. These arrangements were discussed for the Rayleigh number range of $\left(10^{3}, 10^{5}\right.$ and $\left.10^{6}\right)$. The effect of the solid volume fraction of the nanofluid also taken into account, which was ranged as $(0.01 \leqslant \phi \leqslant 0.06)$. As most important result, this study concluded that the best baffle length was $(0.75 \mathrm{~L})$ and positioned at the middle height of the cavity while the two baffles is the optimum choice respecting to heat transfer enhancement. On the other hand, the average Nusselt number augmented with the Rayleigh number and the nanoparticles solid volume fraction increase for both (Al ${ }_{2} \mathrm{O}_{3}$ ) and $(\mathrm{Cu})$, except that the enhancement of $\left(\mathrm{Al}_{2} \mathrm{O}_{3}\right)$ nanoparticles was lower than that of $(\mathrm{Cu})$ nanoparticles. Also, it is approved that the $V$-shaped baffle enhances the heat transfer as the rate gotten by a classical rectangular baffle although it has half its size.
\end{abstract}

Keywords: Parallelogrammical cavity, V-shaped, Baffle, Natural convection, Nanofluid, numerical.

\section{INTRODUCTION}

Due to the widespread applications of the natural convection or buoyancy driven heat transfer and fluid flow in cavities such as aeronautics, aerospace, computers, nuclear energy, civil engineering, solar, geothermal, heliometry and terrestrial equipment, as well as pharmaceutics, food industry and agriculture (Bairi et al, 2014); hence, natural convection in cavities received a clear attention over the recent years as reviewed in literatures (Bairi et al., 2014; Oztop et al., 2014; Hussein et al., 2014; Rostami et al., 2020; Giwa et al., 2020; Mahmud et al., 2020; Emad et al., 2021; Olanrewaju et al., 2021). The heat transfer enhancement is desirable in cavities, so several numerical and experimental studies were accomplished, which is presenting the heat transfer enhancement by using different techniques. Changing the shape or inclination of the cavities (Hussein and Mustafa, 2014; Qi et al., 2017; Selimefendigil, 2017; Majdi et al., 2019; Loganathan et al., 2021) is the common technique. Other researchers enhancing the working fluid properties by using fluid additives such as nanoparticles, which improve the thermal conductivity and the heat transfer performance, where different nanofluids has been reported in literatures (Safiei et al., 2020; Murshed et al., 2020; Ahmadi et al., 2018; Devendiran and Amirtham, 2016; Sidika et al., 2017). As well as, adding baffles of different shapes is one of these techniques of enhancement. Many numerical scientific researches have studied the problem of fins inside cavities investigated this interested field in a baffled enclosure occupied by classical fluids like air.
Regarding the natural convection inside cavities filled by different nanofluids, fewer researches have talked about this problem with numerical scheme. Chahrazed and Samir (2012) investigated the unsteady natural convection inside a differentially heated cavity having a square shape filled by air. Rectangular thin fins placed on the cavity hot wall. Founded that always the optimum fin length was $(0.25$ and 0.5$)$ and the position was $(0.25$ and 0.75$)$. Another researcher named Nardini et al. (2015) studied the natural convection numerically and experimentally inside a square enclosure. The horizontal and vertical walls were made of Plexiglas with four discrete sources to form the cavity. Two insulated baffles, also of Plexiglas were attached in a symmetrical position between the sources along the vertical walls. It was observed that Nusselt sources number increased when Rayleigh number increased while these numbers decreased when the length of the baffle increased for lower sources while it increased for the higher sources. Elatar et al. (2016) preformed a numerical investigation in order to study the natural convection phenomenon inside a square air-filled enclosure. A solid fin of horizontal shape was added on the left hot cavity wall. It was concluded, the fin influence was increased with the length increase, whereas an inverse behavior observed by the fin efficiency. Torabi et al. (2017) examined the natural convection also within a square enclosure filled with air numerically. A thin solid horizontal fin was fitted closely to the cavity hot wall. Where it was observed; the average Nusselt number can be controlled by the movement of the active part of the vertical walls position, and changing the location of the fin on the hot wall.

\footnotetext{
*Corresponding author. Email: zainabghoben@gmail.com
} 
Saeid (2018) located a small heating strip of different shapes at the bottom wall of a square cavity to investigate the effect of fin shape in heating the cavity. The heating strip width was assumed to be $(20 \%)$ of the bottom wall total width. The fin shapes fabricated as: rectangular or one triangular or two opposite triangular and two isosceles triangular shapes. It was founded, the heat transfer enhanced with the height of the fin increase, and the heat transfer in the case of the two opposite triangular fins shape was higher than that of the other shapes. Taw chen et al. (2018) investigated the natural convection in a heated cavity having a horizontal fin on the hot sidewall in a three dimensional (CFD) along with various flow models and experimental data. The average heat transfer coefficient at the fin position of $(35 \mathrm{~mm})$ was (1.7) times that of the $(85 \mathrm{~mm})$ location. Other interesting finding is that the vortices at upper two corners of the cavity and near the upper surface of the fin edge also varied with fin position. Tighchi et al. (2018) employed the Lattice Boltzmann method (LBM) to study the volumetric radiation effects on the laminar natural convection inside a square cavity having a horizontal fin on its hot wall. It was found that the isotherm lines became denser near the cold wall. The maximum Nusselt number ratio founded at the longest fin near the top wall. Raisi (2018) involved the conjugate natural convection of a power-law fluid inside a cavity of a square shape with a pair of conducting baffles embedded on the cavity upper cold wall. The results approved that the baffle length increasing deteriorated the thermal performance of the cavity at high Rayleigh number, while enhanced it at low Rayleigh number. Also, found that the increase in the thermal conductivity ratio from (1) to (100) increased the average Nusselt number by about (14\%). Asl et al. (2019) discovered the effect of different numbers of porous fins attached to the cavity hot wall on the natural convection in the tilted rectangular enclosure. An enhancement of $(41 \%)$ was reported in Nusselt number by using porous fins when comparing to solid ones. Whereas this increase was (20\%) comparing to the case with no fins case. Other studies on the enclosures with attached fins and traditional fluids included in references (Shi and Khodadadi, 2003; Tasnim and Collins, 2004; Bilgen, 2005; Oztop and Bilgen, 2006; Ambarita et al., 2006; Ben-Nakhi and Chamkha, 2006; Sheikhzadeh et al., 2007; Mobedi, 2008).

Mahmoudi et al. (2010) investigated the effects of the geometry of the source of the heat, which was a horizontal baffle having a heat flux of constant value connected to the left vertical wall of the square cavity that filled with $(\mathrm{Cu} /$ water $)$ nanofluid. The determination of the average Nusselt number observed a clear enhancement when the solid volume fraction increase while it decreased with the baffle length increase. Mahmoodi (2011) studied the natural convection inside a cavity of the same shape filled by a number of nanofluids ( $\mathrm{Ag} / \mathrm{water}, \mathrm{Cu} /$ water, $\mathrm{TiO}_{2} /$ water). At a different cooled vertical or insulated horizontal positions in the cavity, an unattached heater was located. Results showed; when Rayleigh number as like as the solid volume fraction increase the rate of heat transfer increases too. Habibzadeh et al. (2011) examined the natural convection of $\left(\mathrm{Al}_{2} \mathrm{O}_{3} /\right.$ water $)$ inside a cavity of square shape. A vertical adiabatic partition was attached to the cavity bottom wall. The cavity vertical walls are differentially heated, the left was hot while the right was cold whereas the horizontals were insulated. Outcomes gave that by increasing Rayleigh number, the average Nusselt number improved, while there was no sensitivity to the solid volume fraction variation. Sayehvand et al. (2012) investigated the natural convection of the $\left(\mathrm{Al}_{2} \mathrm{O}_{3} /\right.$ water $)$ enclosed inside a square cavity. Partitions were attached at the adiabatic horizontal walls of the cavity symmetrically. The effects of the baffle length and Rayleigh number were investigated. It was observed that the Nusselt number enhanced with increasing the Rayleigh number, while it decreased with increasing the baffle length. Guiet et al. (2012) investigated the natural convection, also in a square enclosure occupied by $(\mathrm{Cu} /$ water) nanofluid. At the adiabatic bottom wall, a heater was located, which was assumed isothermal firstly, then generated a heat flux of constant value. Observed that the heat transfer rate improved by Rayleigh number and solid volume fraction increasing. Öztuna and Kahveci (2013) examined the natural convection in a divided partially enclosure of square shape filled with multi water based nanofluids $\left(\mathrm{Cu}, \mathrm{CuO}\right.$, and $\left.\mathrm{Al}_{2} \mathrm{O}_{3}\right)$. An insulated thin partition was attached to the lower adiabatic wall. Observed that an advancement in average Nusselt number by Rayleigh number and the solid volume fraction increase. Whereas, decreased by increasing the partition length. Naoufal et al. (2015) studied the natural convection of $(\mathrm{Cu} /$ water) nanofluid inside a square enclosure. Linking a hot partition vertically to the insulated bottom cavity wall. It was concluded that for all the solid volume fractions the increase in Rayleigh number resulting in an increase of the Nusselt number. In addition, they found that the maximum value of the average Nusselt number occurred as the partition located at the cavity center.

Selimefendigil and Öztop (2016) studied the effect of two nanofluids in an inclined cavity of square shape, evaluated the conjugate natural convection. The partition which was conductive and divided the whole cavity equally. The nanofluids $\left(\mathrm{Al}_{2} \mathrm{O}_{3} /\right.$ water $)$ and $(\mathrm{CuO} /$ water $)$ were filled the left and right hot walls, respectively. The improvement of the heat transfer observed to be $(4.76 \%)$ and $(6.78 \%)$ when the left or the right side of the cavity was occupied by nanofluid with solid volume fraction of (4\%). The other part of the cavity was filled with water only. Armaghani et al. (2016) investigated the natural convection of $\left(\mathrm{Al}_{2} \mathrm{O}_{3} /\right.$ water $)$ nanofluid in an L-shaped and baffled cavity. The vertical left and the bottom walls were maintained at constant hot temperature. The middle horizontal and the right vertical walls and the baffle were at constant cold temperature, the other walls were insulated. The results showed that the aspect ratio increase enhancing the heat transfer. Also, the nanofluid impact on Nusselt number has a greater grow by increasing the length of the baffle. While the nanofluid has less effect on the cavity cooling, causing the heat transfer raise. Siavashi et al. (2018) presented the natural convection study of $(\mathrm{Cu} /$ water $)$ inside a square cavity, where its hot wall having an array of porous fins. Numerical results indicated that the porous fins were improved the heat transfer and the Nusselt number. As like as the increase in the length of these fins or its number had insignificant effect on the Nusselt number in strong field flow. Bendaraa et al. (2019) investigated the natural convection inside a cavity of square shape and filled by the $(\mathrm{Cu} /$ water) nanofluid. The fins were considered conductive having different lengths and distributed at different locations. It was found that adding fins on the cold right and the adiabatic horizontal walls results in an increase in the average Nusselt number. While it decreased where the fin located on the left hot wall. Ma et al. (2019) investigated the natural convection in the presence of a magnetic field in a baffled U-shaped enclosure by employing (LBM). The results demonstrated that the increase of Rayleigh number, nanoparticle solid volume fraction and aspect ratio causing the average Nusselt number increase. Besides, the effect of the Rayleigh number on the heat transfer enhancement became more significant at higher aspect ratio.

Hussein et al. (2020) worked on the natural convection in an inclined rectangular cavity, filled with $(\mathrm{Cu} /$ water $)$ and $\left(\mathrm{Al}_{2} \mathrm{O}_{3} /\right.$ water $)$ nanofluids respectively. A horizontal thin cold baffle was close attached to the hot left wall. Founded that an enhancement in the intensity of fluid flow in the enclosure was observed as the Rayleigh number, the solid volume fraction, the baffle length or the aspect ratio increased. While the inclination angle increase reduced it. Keramat et al. (2020) performed the natural convection of the $\left(\mathrm{Al}_{2} \mathrm{O}_{3} /\right.$ water $)$ nanofluid inside an $\mathrm{H}$-shaped cavity. The bottom cavity wall and the top rib were kept at a hot temperature. The two sidewalls were kept at the lower temperature, the other walls were insulated. The results showed that the heat transmission was improved by Rayleigh number enhancement and nanoparticle volume fraction. In addition, the baffle installation at the bottom rib under a non-adiabatic boundary condition improved the heat transfer. Du et al. (2020) examined the ventilation cavity filled with the hybrid nanofluid $\left(\mathrm{Cu} / \mathrm{Al}_{2} \mathrm{O}_{3} /\right.$ water $)$ where a vertical hot baffle touched at the center of the cavity. The cavity walls were insulted. The positions of the opening ports were distributed along the diagonal of the vertical walls. Results indicated that the percentage augmentee of the solid volume 
fraction enhanced the heat transfer rate. Nia et al. (2020) used the (LBM) to simulate the $(\mathrm{Cu} /$ water) nanofluid in a baffled $\mathrm{L}$-shaped enclosure. The results showed that at low Rayleigh number, the addition of baffle always enhanced the natural convection. At high Rayleigh number, just the longer baffle length can improve the natural convection regardless of its positioning. The longer baffle was always more effective with the proper positioning and the case baffle length $(0.3 \mathrm{~m})$ and position of $(0.4 \mathrm{~m})$ was the most effective in all conditions. It was observed from literature that there are a few studies on the complex baffles except (Saeid, 2018; Keramata et al., 2020) whereas almost researches investigated the classical rectangular baffle. In this study the V-shaped baffle of different length, locations and number attached to the inner wall of a parallelogrammical cavity were studied for the first time.

\section{MATHEMATICAL FORMULATION}

\subsection{The geometry}

The geometry of this study was a parallelogrammical cavity with a very thin V-shape baffle attached to the inner side of the right wall of the cavity in different numbers, lengths and locations. The left and the right walls were kept hot and cold respectively, while the other horizontal walls were insulated. At the cold wall, a baffle was attached. The cavity has $(\mathrm{L})$ sidewall length, the baffle length was varying as $\left(0.25 \mathrm{~L} \leqslant \mathrm{lb}_{\mathrm{b}} \leqslant\right.$ $0.75 \mathrm{~L})$ while its base width $(\mathrm{wb})$ was $(0.04 \mathrm{~L})$ as shown in Fig. (1). As like as, the baffle length, the baffle positioned at different locations $(\mathrm{hb})$ along the right cold wall which was at $(0.25 \mathrm{~L}, 0.5 \mathrm{~L}, 0.75 \mathrm{~L})$ from the bottom horizontal wall. The cavity filled with two unsimilar water-based nanofluids $\left(\mathrm{Al}_{2} \mathrm{O}_{3}, \mathrm{Cu}\right)$, then compared with pure water. The properties of pure water and nanofluids were previewed in Table (1).

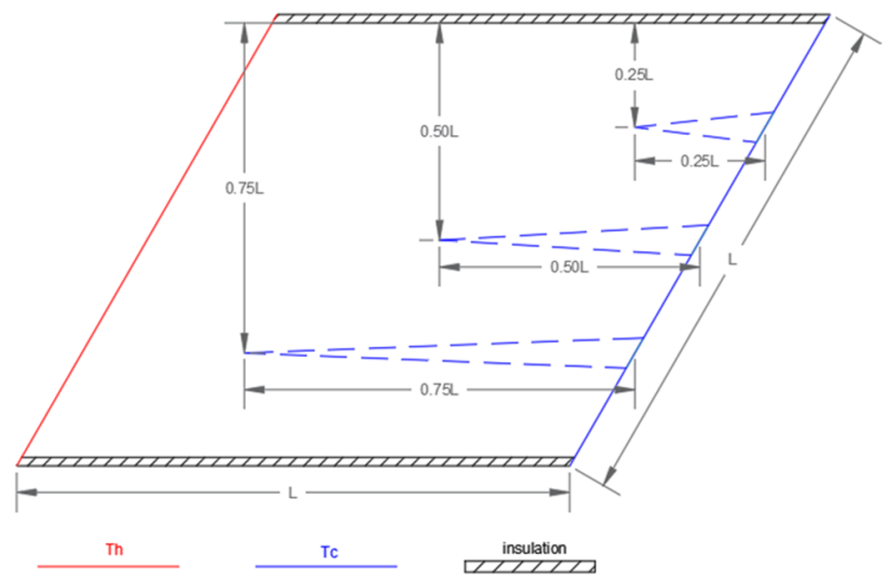

Fig. 1 The cavity configuration with the different suggested baffle number, lengths and locations.

Table 1 The physical properties of the pure water and the nanofluids (Lai and Yang, 2011; Hussein and Mustafa, 2017).

\begin{tabular}{|l|l|l|l|l|}
\hline & $\rho$ & $C_{p}$ & $K$ & $\beta$ \\
\hline Pure Water & 997.1 & 4179 & 0.613 & 0.0002100 \\
\hline $\mathrm{Al}_{2} \mathrm{O}_{3}$ & 3880 & 765 & 40 & 0.0000085 \\
\hline $\mathrm{Cu}$ & 8933 & 385 & 401 & 0.0000167 \\
\hline
\end{tabular}

\subsection{The governing equations}

The assumptions selected for describing the governing equations are:

1. A steady, two-dimensional, laminar, incompressible flow.

2. The heat generation and the radiation heat transfer are neglected.

3. The base fluid and the nanoparticles assumed in a thermal equilibrium state.
4. The thermophysical properties of the mixture are considered constant. While the density variation determined based on the Boussinesq approximation.

The non-dimensionless form of the governing equations in the present work which are given as (Hussein and Mustafa, 2017):

The continuity equation:

$\frac{\partial U}{\partial X}+\frac{\partial V}{\partial Y}=0$

The momentum equations:

$U \frac{\partial U}{\partial X}+V \frac{\partial U}{\partial Y}=-\frac{\partial P}{\partial X}+\frac{1}{\rho_{n f} \alpha_{f}}\left(\mu_{n f}\right)\left(\frac{\partial^{2} U}{\partial X^{2}}+\frac{\partial^{2} U}{\partial Y^{2}}\right)$

$U \frac{\partial V}{\partial X}+V \frac{\partial V}{\partial Y}=-\frac{\partial P}{\partial Y}+\frac{1}{\rho_{n f} \alpha_{f}}\left(\mu_{n f}\right)\left(\frac{\partial^{2} V}{\partial X^{2}}+\frac{\partial^{2} V}{\partial Y^{2}}\right)+\frac{(\rho \beta)_{n f}}{\rho_{n f} \beta_{f}} \operatorname{RaPr} \theta$

The energy equation:

$U \frac{\partial \theta}{\partial X}+V \frac{\partial \theta}{\partial Y}=\frac{K_{n f}}{\alpha_{f}\left(\rho c_{p}\right)_{n f}}\left(\frac{\partial^{2} \theta}{\partial X^{2}}+\frac{\partial^{2} \theta}{\partial Y^{2}}\right)$

Where the dimensionless variables can be defined as:

$X=\frac{x}{L}, Y=\frac{y}{L}, U=\frac{u L}{\alpha_{f}}, V=\frac{v L}{\alpha_{f}}, \theta=\frac{T-T_{c}}{T_{h}-T_{c}}, P=\frac{p L^{2}}{\rho_{n f} \alpha_{f}^{2}}$,

$R a=\frac{g \beta_{f}\left(T_{h}-T_{c}\right) L^{3}}{v_{f} \alpha_{f}}, \operatorname{Pr}=\frac{v_{f}}{\alpha_{f}}, L_{b}=\frac{l_{b}}{L}, W_{b}=\frac{w_{b}}{L}$

The nanofluid properties are calculated by using the appropriate models which is given by (Oztop et al., 2012; Abu-Nada and Oztop, 2009):

$\alpha_{n f}=\frac{K_{n f}}{\left(\rho c_{p}\right)_{n f}}$

$\mu_{n f}=\frac{\mu_{f}}{(1-\varphi)^{2.5}}$

$\rho_{n f}=(1-\varphi) \rho_{f}+\varphi \rho_{p}$

$\left(\rho c_{p}\right)_{n f}=(1-\varphi)\left(\rho c_{p}\right)_{f}+\varphi\left(\rho c_{p}\right)_{p}$

$(\rho \beta)_{n f}=(1-\varphi)(\rho \beta)_{f}+\varphi(\rho \beta)_{p}$

$K_{n f}=K_{f} \frac{\left(K_{p}+2 K_{f}\right)-2 \varphi\left(K_{f}-K_{p}\right)}{\left(K_{p}+2 K_{f}\right)+\varphi\left(K_{f}-K_{p}\right)}$

The previous dimensionless equations are solved using the following non-dimensional boundary conditions:

1. The left sidewall of the cavity maintained at hot temperature:

$$
\theta=1 \quad U=V=0
$$

2. The right sidewall of the cavity and the baffle maintained at cold temperature:

$$
\theta=0 \quad U=V=0
$$

3. The top and bottom horizontal walls are kept insulated:

$$
\frac{\partial \theta}{\partial x}=0 \quad U=V=0
$$

\subsection{The local and average Nusselt numbers}

The local Nusselt number at the walls is defined as (Abu-Nada and Oztop, 2009):

$\mathrm{Nu}=-\left(\frac{\mathrm{k}_{\mathrm{nf}}}{\mathrm{k}_{\mathrm{f}}}\right) \frac{\partial \theta}{\partial \mathrm{X}}$

The average Nusselt number is presented as (Ghasemi and Aminossadati, 2009):

$\mathrm{Nu}_{\mathrm{av}}=\int_{0}^{1} \mathrm{Nu}(\mathrm{x}) \mathrm{dx}$

\section{THE NUMERICAL METHODOLOGY: STUDY OF THE GRID INDEPENDENCY AND THE VALIDATION}

The finite element scheme (FEM) was used for simulating and solving the governing equations along with the boundary conditions. Triangular mesh on a parallelogrammical cavity including a V-shaped baffle and filled with nanofluid were generated in this study as shown in Fig. (2). The grid independence study was presented for the number of elements in the entire cavity domain as tabulated in Table (2). Considering the accuracy and time consumed, a mesh of (19205) elements including (509) boundary elements has been elected for all the computations in the present study. The present numerical results obtained from simulation using FEM are validated with significant researchers to ensure the accuracy. The contours of the isotherm lines and the streamlines of the 
present work are validated with those of Sayehvand et al. [35] for ( $\mathrm{Ra}=10^{5}, L_{b}=0.5, \varphi=0.2$ ) giving a good agreement as shown in Fig. (3). For more accuracy, the present average Nusselt number were also validated as tabulated in Table (3).

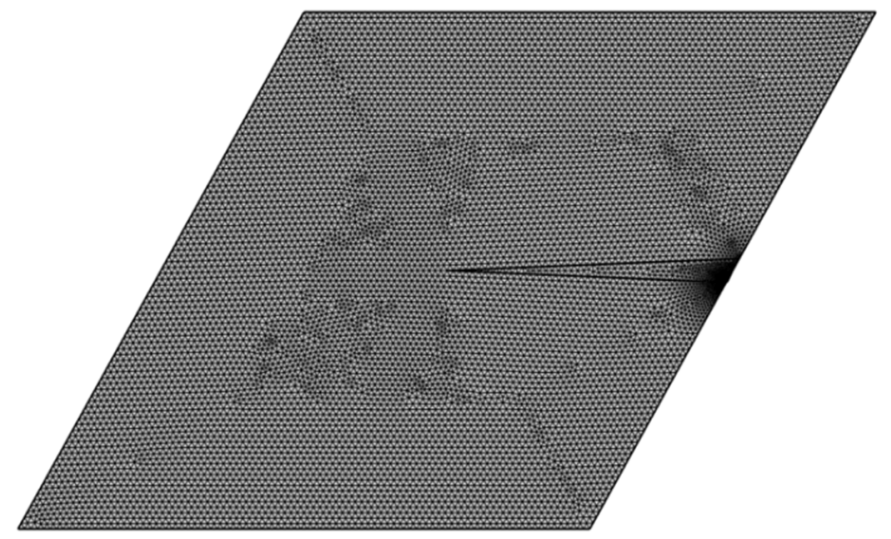

Fig. 2 The mesh distribution for the case of single baffle with $\left(L_{b}=0.5\right.$ and $H_{b}=0.5$ ).

Table 2 The grid independence test on Nuavg value stability for $\mathrm{Ra}=106$ and $\varphi=0.06$.

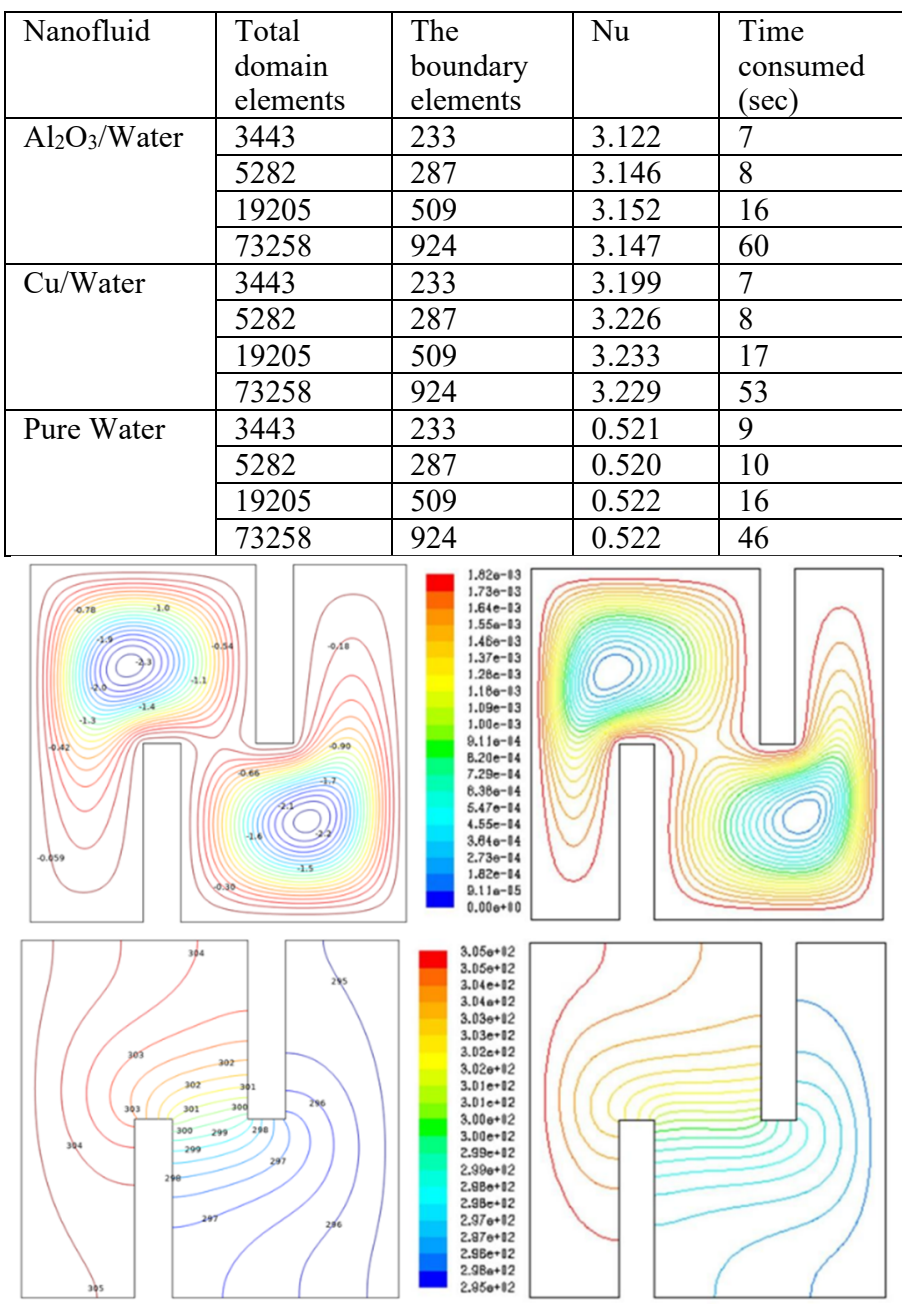

Fig. 3 The validation of the present study (left) with (Sayehvand et al. (2012)) (right) at $\mathrm{Ra}=10^{5}$ for streamlines (up) and isotherm lines (down).
Table 3 Comparison of the $\mathrm{Nu}_{\text {avg }}$ values with previous published data

\begin{tabular}{|l|l|l|l|}
\hline Author & $\mathrm{Ra}=10^{4}$ & $\mathrm{Ra}=10^{5}$ & $\mathrm{Ra}=10^{6}$ \\
\hline Ho et al. (2008) & 2.246 & 4.522 & 8.825 \\
\hline Mahmoudi (2010) & 2.248 & 4.502 & 9.147 \\
\hline Sayehvand et al. (2012) & 2.241 & 4.526 & 8.919 \\
\hline Present & 2.220 & 4.552 & 8.898 \\
\hline
\end{tabular}

\section{RESULTS AND DISCUSSION}

The effect of the different parameters on the fluid flow and the heat transfer fields according to the streamlines and the isotherm lines contours as like as the average and the local Nusselt numbers were discussed in the following sections:

\subsection{Effect of Rayleigh number on non-baffled and baffled cavities}

The effect of Rayleigh number (Ra) on the streamlines $(\Psi)$ contour presented in Fig. (4). Which was observed that the absolute values of the maximum stream functions were $(0.23,8.1,19.7)$ for baffled case $\left(L_{b}=0.5, H_{b}=0.5\right)$, whereas it was $(0.64,9.7,20.1)$ for non-baffled case corresponding to Rayleigh number of $\left(10^{3}, 10^{5}, 10^{6}\right)$, respectively. The increase in absolute stream function value were resulted due to the increase in the movement of the fluids rapidly by increasing Rayleigh number, but this increase was reduced by attaching a baffle to the cavity. Also, the strength of the flow circulation enhances with Rayleigh number increase. Where the effect of the buoyancy force inside the cavity become stronger leading to the rapid increase of the improvement in the stream function values. The vortices core for the non-baffled cavity taking a circle shape for $\left(\mathrm{Ra}=10^{3}\right)$ while it has an elongated ellipse shape for $\left(\mathrm{Ra}=10^{5}\right)$ and this elongated ellipse tend to be narrow at the mid length for $\left(\mathrm{Ra}=10^{6}\right)$.

For the baffled cavity, the vortices taking a triangular shape which is completely below the baffle height level for $\left(\mathrm{Ra}=10^{3}\right)$, while it is touch the baffle height level for $\left(\mathrm{Ra}=10^{5}\right)$. For $\left(\mathrm{Ra}=10^{6}\right)$ it takes a vertical rectangular shape at a location where the baffle level is at the center of it. As like as, the isotherm lines $(\theta)$ contour for $\left(\mathrm{Al}_{2} \mathrm{O}_{3} /\right.$ water $)$ nanofluid with ( $\left.\varphi=0.06, L_{b}=0.5, H_{b}=0.5\right)$ for non-baffled and baffled cavities were presented in Fig. (5). The non-baffled cavity isotherm lines for $\left(\mathrm{Ra}=10^{3}\right)$ having nearly a uniform distribution showing that the conduction is the heat transfer form in this region, while for $\left(\mathrm{Ra}=10^{5}\right.$ and $\left.10^{6}\right)$. A clear irregularity in isotherms distribution appears, which is explain the heat transfer by convection domination. The baffled cavities isotherms also have the same behavior except the clear modification in the nonuniformity distribution at the region around the baffle body through the cavity.

The effect of Rayleigh number on the average Nusselt number was previewed in Fig. (6) which showed that attaching a baffle to the cavity was increasing the average Nusselt number and this increase also enhanced before and after Rayleigh number of $\left(10^{5}\right)$. Whereas at $\left(\mathrm{Ra}=10^{5}\right)$, the Nusselt number nearly equal for non-baffled and baffled cavities. For $(\varphi=0.06)$, the enhancement in the average Nusselt number was $(40 \%)$ over the non-baffled at $\left(\mathrm{Ra}=10^{3}\right)$ and $(10 \%)$ at $\left(\mathrm{Ra}=10^{6}\right)$. Whereas no enhancement over the non-baffled cavity at $\left(\mathrm{Ra}=10^{5}\right)$. As well as the Local Nusselt number values along the inclined heated wall of the cavity was presented in Fig. (7). For the non-baffled and the baffled cavities, which coincide with the average Nusselt number behavior according to Rayleigh number effect. The peak local Nusselt number value at each Rayleigh number occurs at a specified location along the heated wall. These peaks occur at locations of non-higher than $\left(H_{b}=0.25\right)$ of the cavity height for Rayleigh numbers of $\left(10^{5}\right.$ and $\left.10^{6}\right)$ while the peak or the maximum local Nusselt number for Rayleigh number of $\left(10^{3}\right)$ occurs at the top end of the heated wall. Also, the local Nusselt number values at Rayleigh number of $\left(10^{5}\right.$ and $\left.10^{6}\right)$ for baffled cavity was higher than non-baffled below the location of the baffle. While it was lower than it above the baffle location. Whereas, it was always higher for the baffled cavity at Rayleigh number of $\left(10^{3}\right)$. 

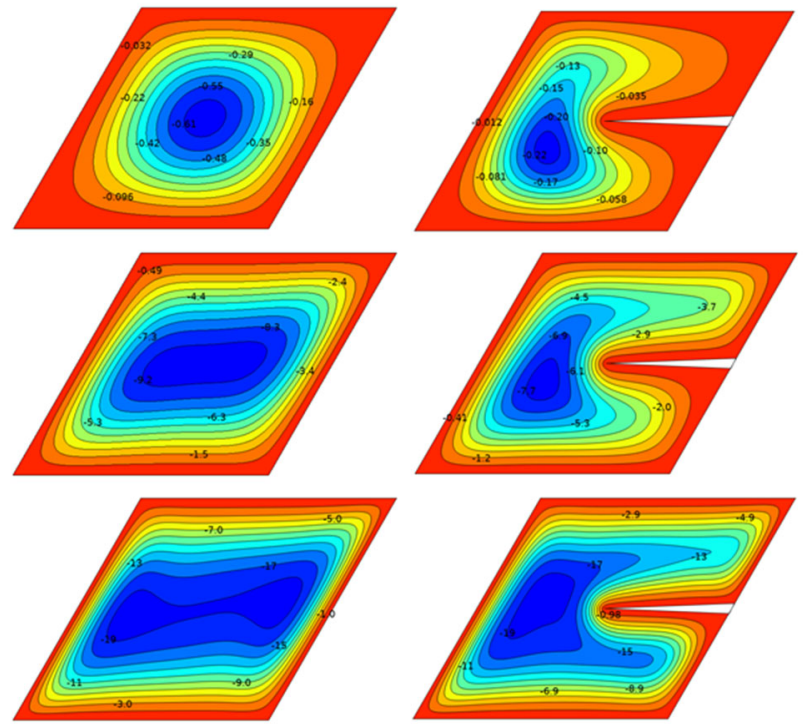

Fig. 4 Effect of (Ra) on the streamlines at $\varphi=0.06$ for: non-baffled (left) and baffled (right) cavities.
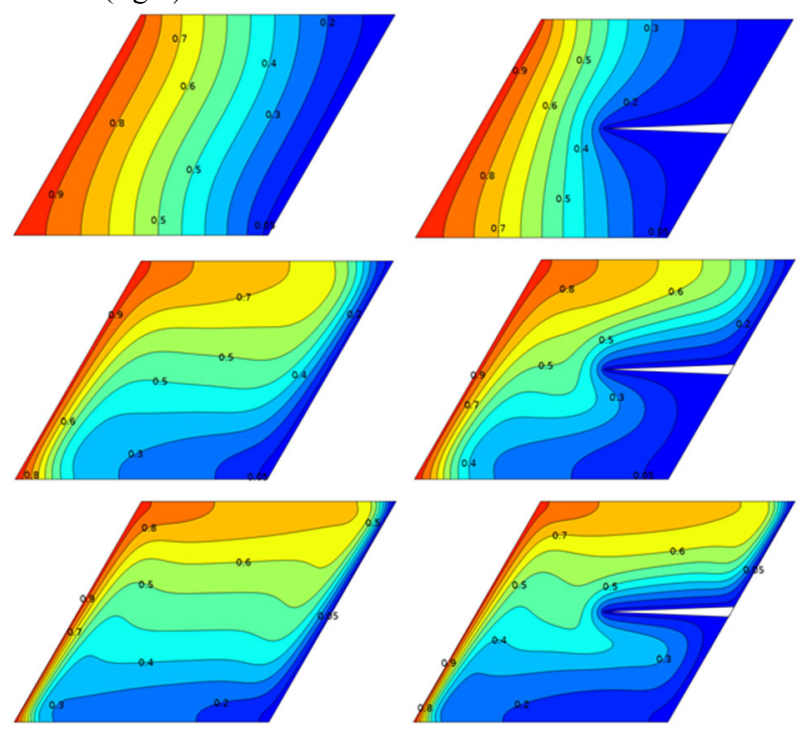

Fig. 5 Effect of $(\mathrm{Ra})$ on the isotherms at $\varphi=0.06$ for: non-baffled (left) and baffled (right) cavities.

\subsection{Effect of baffle location}

The Fig. (8) showing the effect of baffle location $\left(H_{b}\right)$ on the streamlines and the isotherm lines at $\left(\mathrm{Ra}=10^{5}\right.$ and $\left.\varphi=0.06\right)$. While Fig. (9) and Fig. (10) presented the effect on the average and local Nusselt numbers. The maximum absolute stream function of the baffle located at $(0.25)$ position was $(0.3,8.5,21.1)$, for $(0.5)$ position was $(0.23,8.1,19.7)$ while it was $(0.5,9.4,22.7)$ for $(0.75)$ location for Rayleigh number $\left(10^{3}, 10^{5}, 10^{6}\right)$ respectively. These results explain the stronger natural convection inside the cavity with $(0.75)$ baffle position comparing to those positions of $(0.25$ and 0.5$)$ in sequence. On the other hand, attaching the baffle at different locations along the cavity height has an effect on the isotherms uniformity which is deformed clearly and tend to be curved. This effect appears in the average and local Nusselt numbers enhancement as shown in Fig. (9) and Fig. (10). It was noticed that the sequence of locations with respect to the enhancement occurs when the baffle attached at $(0.25-$ $0.75-0.5)$ along the cavity height for $\left(\mathrm{Ra}=10^{5}\right)$. While it was $(0.25-0.5-$ $0.75)$ for $\left(\mathrm{Ra}=10^{3}\right)$ and $(0.5-0.75-0.25)$ for $\left(\mathrm{Ra}=10^{6}\right)$. Noticing that the enhancement of the locations $(0.25$ and 0.75$)$ is equal which in turn less than the $(0.5)$ location enhancement by $(4 \%)$.
On the other hand, the location of the maximum local Nusselt number not affected by the baffle location for the same baffle length. The average Nusselt number before $\left(\mathrm{Ra}=10^{5}\right)$ of the $(0.25)$ location was the best while after this region the $(0.5)$ location become the best location for heat transfer enhancement. It was concluded that the position at the center of the vertical wall is the best location because that the $\left(\mathrm{Ra}=10^{6}\right)$ was the more interested region in laminar natural convection.

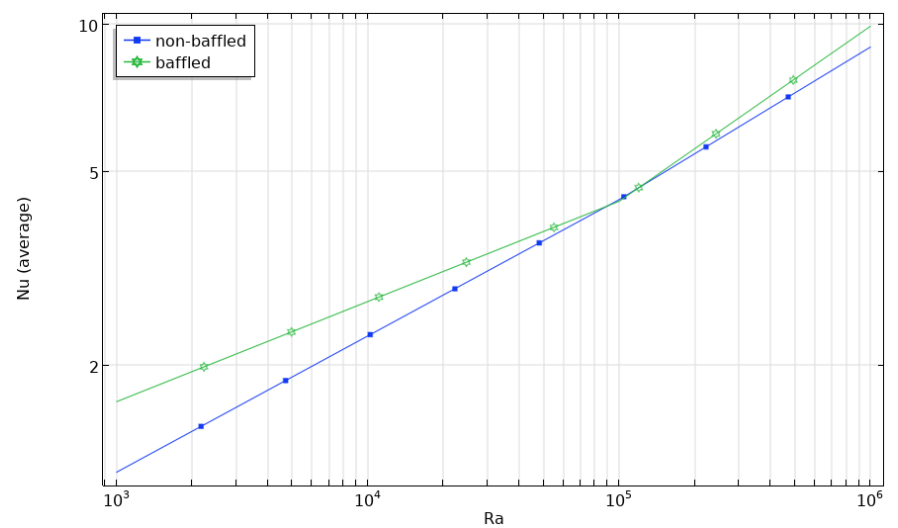

Fig. 6 Effect of $(\mathrm{Ra})$ on the average $(\mathrm{Nu})$ at $\varphi=0.06$ for non-baffled and baffled cavities.

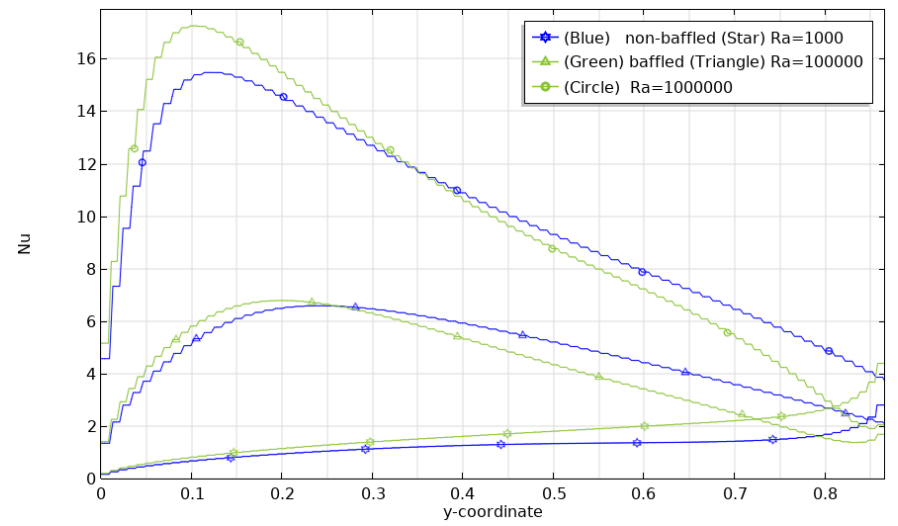

Fig. 7 The local $(\mathrm{Nu})$ along the heated wall at $\varphi=0.06$ for non-baffled and baffled cavities.
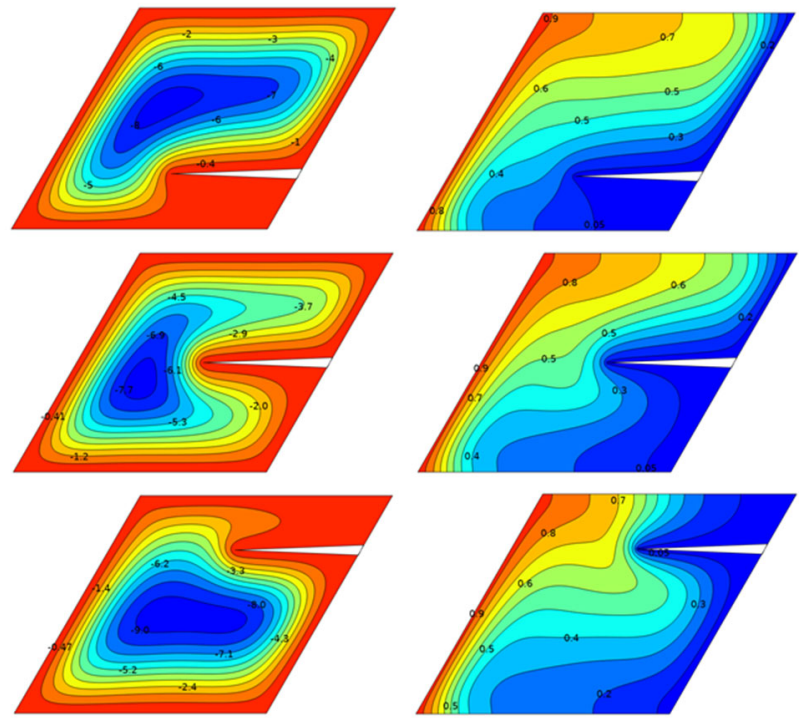

Fig. 8 Effect of baffle location $\left(H_{b}\right)$ at $\mathrm{Ra}=10^{5}$ and $\varphi=0.06$ on the streamlines (left) and isotherms lines (right). 


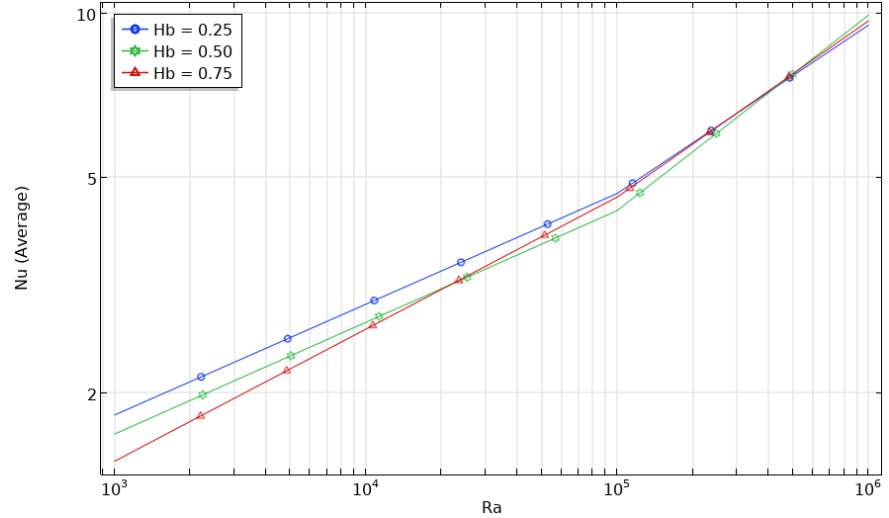

Fig. 9 Effect of baffle location $\left(H_{b}\right)$ versus $(\mathrm{Ra})$ at $\varphi=0.06$ on the average $(\mathrm{Nu})$.

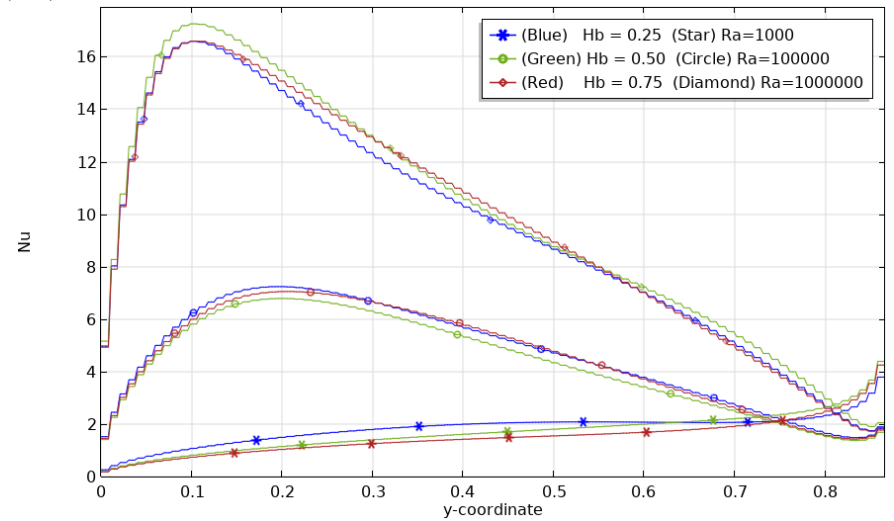

Fig. 10 Effect of baffle location $\left(H_{b}\right)$ at $\varphi=0.06$ on the local $(\mathrm{Nu})$ along the heated wall for different $(\mathrm{Ra})$.

\subsection{Effect of number of baffles}

The Fig. (11) presented the streamlines and the isotherm lines contours for different baffle number $(1,2$ and 3$)$ at $\left(\mathrm{Ra}=10^{5}\right.$ and $\left.\varphi=0.06\right)$. Whereas the Fig. (12) and Fig. (13) showed the effect of the baffle number on the average and local Nusselt numbers respectively. The maximum absolute stream function for the single baffle was $(0.23,8.1,19.7)$ and $(0.24,8.2$, $21.8)$ for double baffles whereas it was $(0.17,7.5,19.3)$ for triple baffles according to Rayleigh number of $\left(10^{3}, 10^{5}, 10^{6}\right)$, respectively.

The higher absolute stream function values were in the case of two baffles. The core of the streamlines takes the configuration of triangle for single and double baffles while it takes an ellipse shape for the triple baffles.

The best enhancement of the average Nusselt number was founded for the double baffles case which is about $(7 \%)$ over the single and the triple baffles cases at $\left(\mathrm{Ra}=10^{5}\right)$ and about $(1 \%$ and $7 \%)$ for $\left(\mathrm{Ra}=10^{6}\right)$. Where the enhancement of average Nusselt number was became very close for the single and double baffles with Rayleigh number increase. The local Nusselt number for the single baffle along the heated wall of the cavity was higher than that of double or tribble baffles.

\subsection{Effect of baffle length}

The contours of the streamlines and the isotherms for various baffle dimensionless length $\left(\mathrm{L}_{\mathrm{b}}\right)$ of $(0.25,0.5,0.75)$ at $\left(\mathrm{Ra}=10^{5}, \varphi=0.06\right)$ were demonstrated in Fig. (14). While the effect of the baffle length on the average and local Nusselt numbers were presented in Fig. (15) and Fig. (16).

It has been noticed that the absolute value of the maximum stream functions was decreased with baffle length and this decrease was $(52 \%)$ by increasing the length from $(0.25$ to 0.5$)$ and from $(0.5$ to 0.75$)$ for $(\mathrm{Ra}=103)$. Whereas this rate of increase decreases with Rayleigh number increase which was (12\% and $27 \%)$ for the same previous baffle length for $\left(\mathrm{Ra}=10^{5}\right)$ and $(1 \%$ and $9 \%)$ for $\left(\mathrm{Ra}=10^{6}\right)$, in sequence.

On the other hand, the increment in baffle length changes the isotherms pattern, where the isotherms around the baffle become nonlinear and the nonlinearity increase with the baffle length.

Also, it was observed that the average and local Nusselt numbers enhanced with the baffle length, observing that for length of $(0.75)$ the local Nusselt number has two peak values above the baffle body location (lower peak) and below it (higher peak) for $\left(\mathrm{Ra}=10^{5}\right)$. The peak value for $\left(\mathrm{Ra}=10^{3}\right)$ occurred before the end of the cavity height and has a clear growth comparing to the $(0.25$ and 0.5$)$ lengths which was presented in Fig. (16).
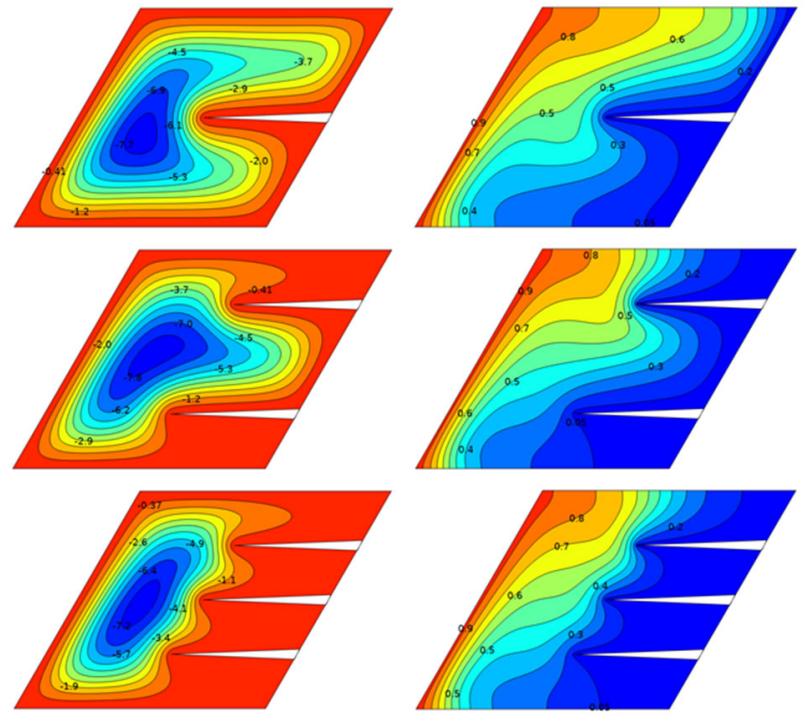

Fig. 11 Effect of number of baffles at $\mathrm{Ra}=10^{5}$ and $\varphi=0.06$ on the streamlines (left) and the isotherms (right).

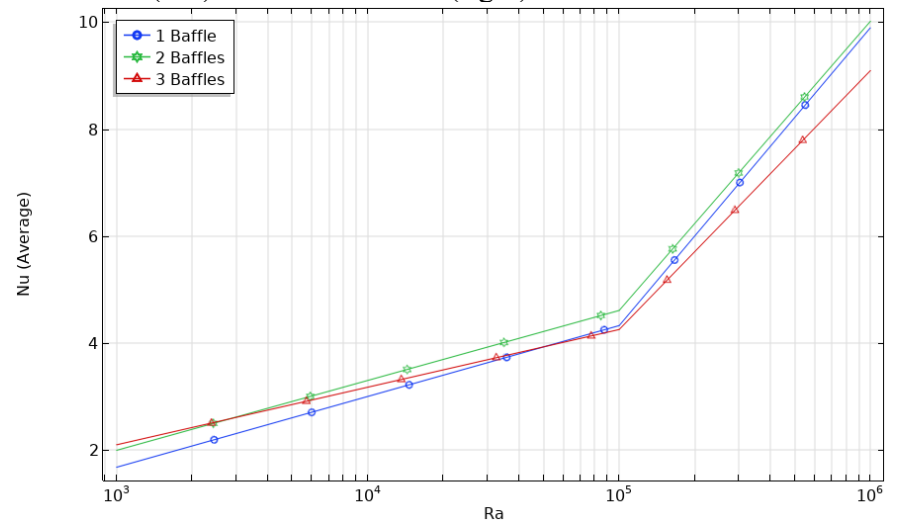

Fig. 12 Effect of number of baffles on the average $(\mathrm{Nu})$ at $\varphi=0.06$.

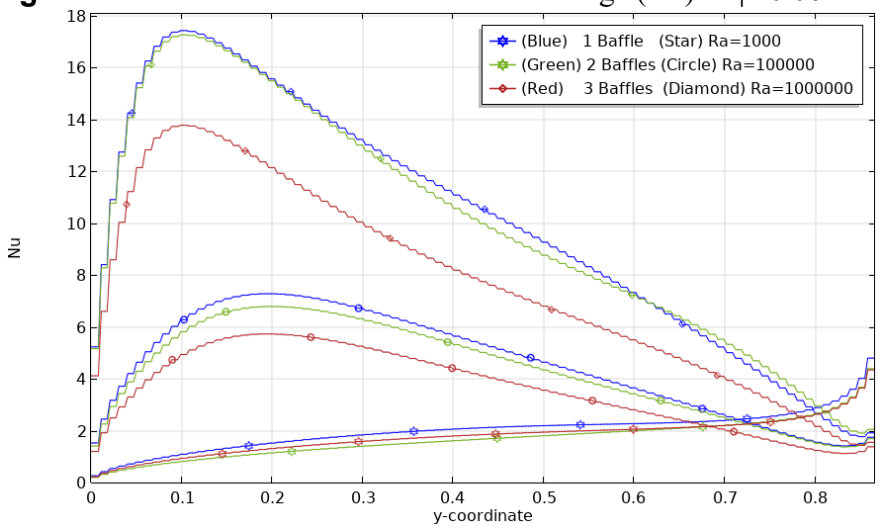

Fig. 13 Effect of number of baffles on the local $(\mathrm{Nu})$ at $\varphi=0.06$. 

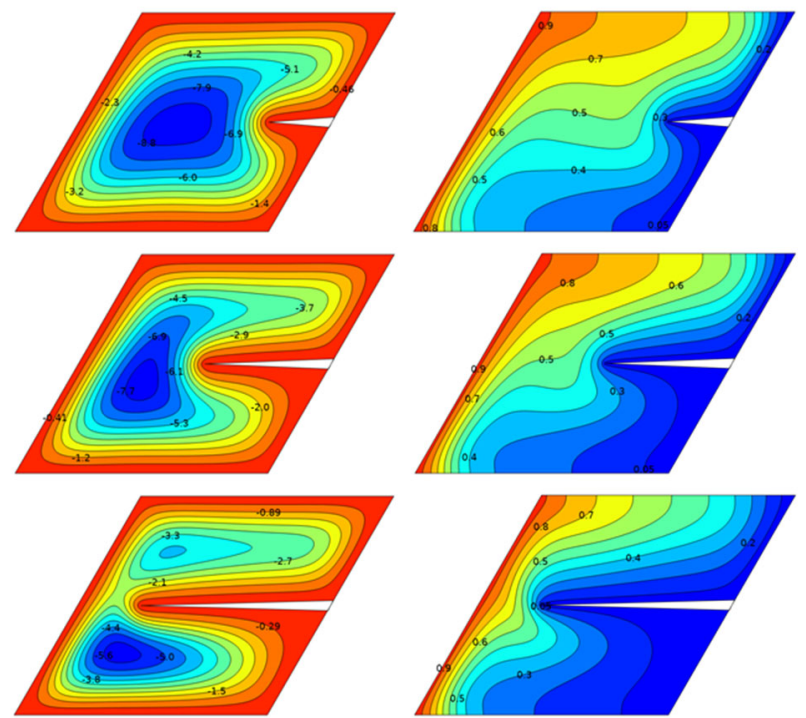

Fig. 14 Effect of baffle length $\left(L_{b}\right)$ at $\mathrm{Ra}=10^{5}$ and $\varphi=0.06$ on the streamlines (left) and the isotherms (right).

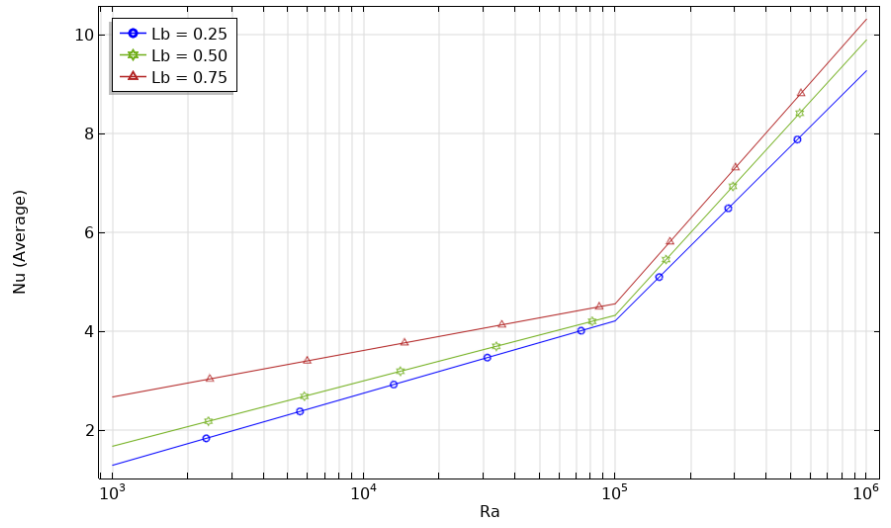

Fig. 15 Effect of baffle length $\left(L_{b}\right)$ on the average $(\mathrm{Nu})$ at $\varphi=0.06$.

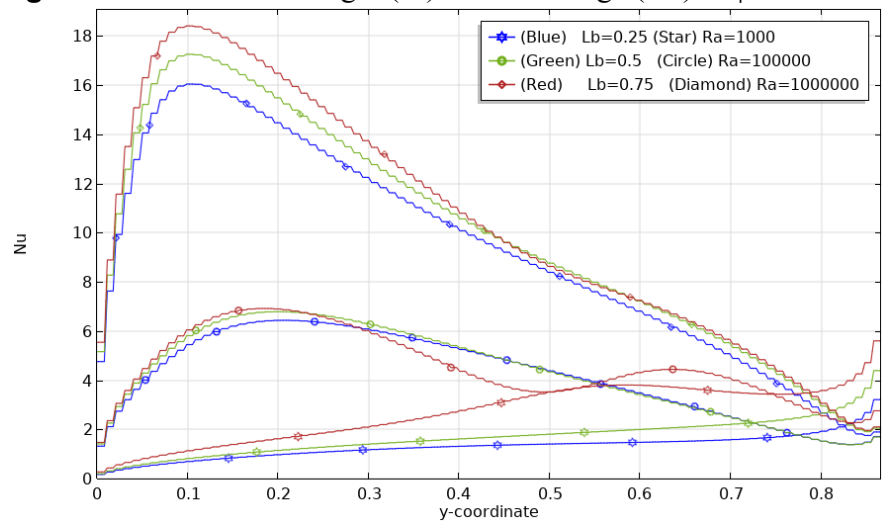

Fig. 16 Effect of baffle length $\left(L_{b}\right)$ on the local $(\mathrm{Nu})$ at $\varphi=0.06$.

\subsection{Effect of nanofluid type and solid volume fraction}

The Fig. (17) presents the stream lines and the isotherm lines at $\left(\mathrm{Ra}=10^{5}\right.$ and $\varphi=0.06)$ for pure water and two types of water-based nanofluids $\left(\mathrm{Al}_{2} \mathrm{O}_{3} /\right.$ water $)$ and $(\mathrm{Cu} /$ water $)$. The stream function maximum absolute value increases with Rayleigh number increase for pure water and both the nanofluids as well as its increase with the solid volume fraction of the nanoparticles. On the other hand, the maximum absolute stream function values for $(\mathrm{Cu} /$ water $)$ was higher than that of $\left(\mathrm{Al}_{2} \mathrm{O}_{3} /\right.$ water $)$ for the same conditions. The uniformity of the isotherm lines increased strongly when comparing the nanofluids with the pure water. Also, the enhancement of the heat transfer by adding nanoparticles comparing to the pure water was appeared clearly in the average Nusselt number enhancement as shown in Fig. (18). Whereas this increase increased with Rayleigh number. It was shown that the increase in solid volume fraction $(\varphi)$ causing increase in both average and local Nusselt numbers for both $\left(\mathrm{Al}_{2} \mathrm{O}_{3} /\right.$ water) and (Cu/water) as shown in Fig. (19) and Fig. (20). Although the enhancement of these two nanofluids is very close but that of $(\mathrm{Cu} /$ water $)$ nanofluid was higher than that of $\left(\mathrm{Al}_{2} \mathrm{O}_{3} /\right.$ water $)$ nanofluid. For both the nanofluids; the increase in average Nusselt number for two different nanoparticles concentration reach its minimum value at Rayleigh number of $\left(10^{5}\right)$ whereas, this increase being higher at both Rayleigh number of $\left(10^{3}\right.$ and $\left.10^{6}\right)$.
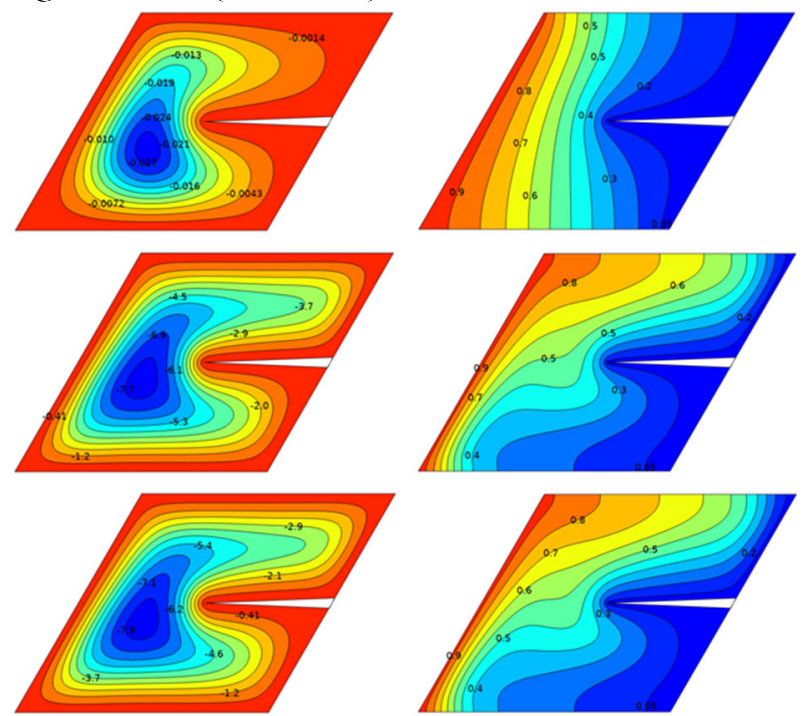

Fig. 17 Comparison of the streamlines (left) and the isotherms (right) for pure water, $\left(\mathrm{Al}_{2} \mathrm{O}_{3} /\right.$ water) and $\left(\mathrm{Cu} /\right.$ water) (up to down) at $\mathrm{Ra}=10^{5}$ and $\varphi=0.06$.

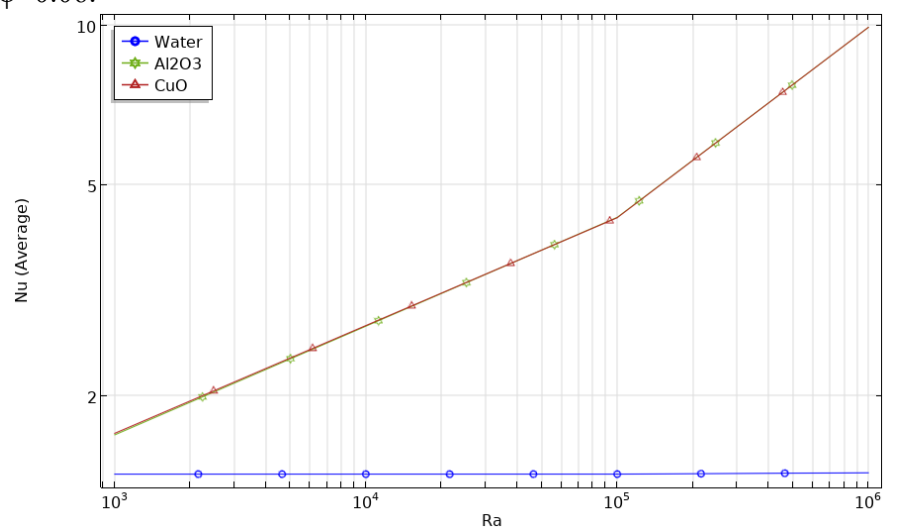

Fig. 18 Comparison of pure water with $\left(\mathrm{Al}_{2} \mathrm{O}_{3} /\right.$ water $)$ and $(\mathrm{Cu} /$ water $)$ respect to the average $(\mathrm{Nu})$ at $\varphi=0.06$.

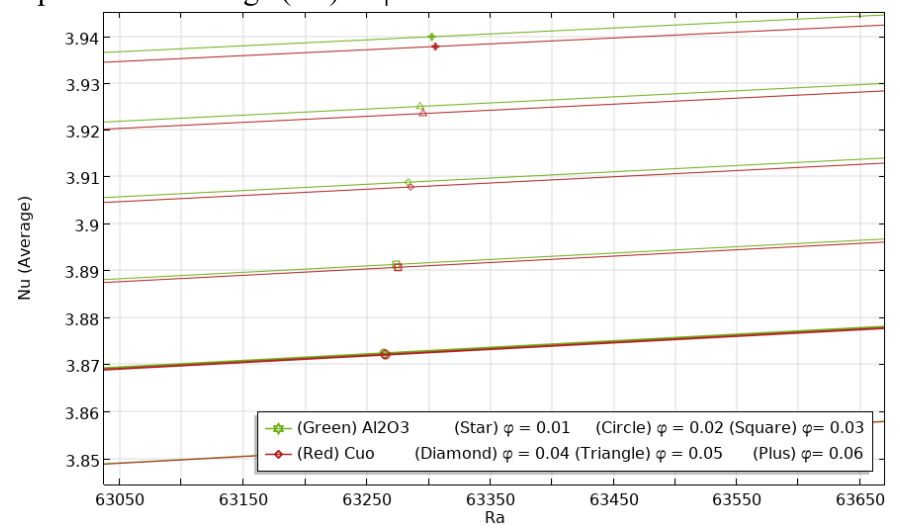

Fig. 19 Effect of nanofluids solid volume fraction on the average $(\mathrm{Nu})$ for $\left(\mathrm{Al}_{2} \mathrm{O}_{3} /\right.$ water $)$ and $(\mathrm{Cu} /$ water $)$. 


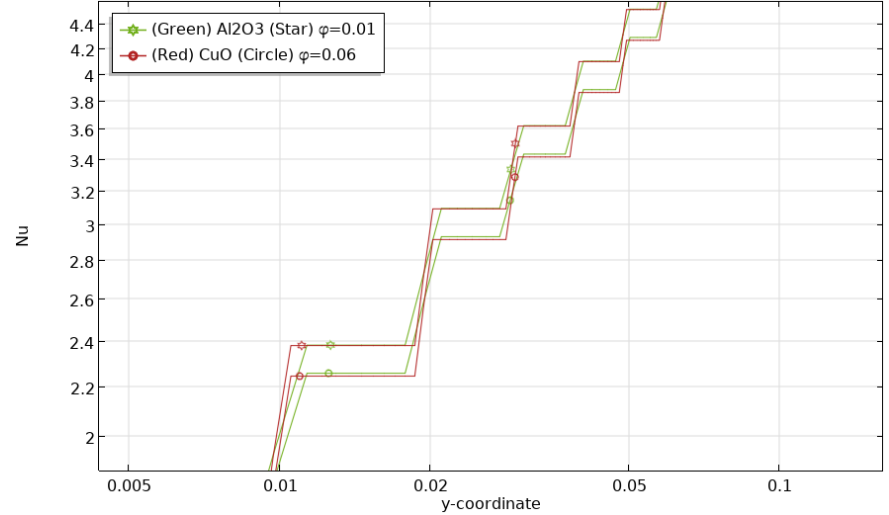

Fig. 20 Effect of nanofluids solid volume fraction on the local $(\mathrm{Nu})$ for $\left(\mathrm{Al}_{2} \mathrm{O}_{3} /\right.$ water $)$ and $(\mathrm{Cu} /$ water $)$.

\subsection{Comparison with classical rectangular baffle shape}

The streamlines and isotherm lines contours of the comparison of the Vshaped and classical (rectangular) baffles at two different Rayleigh number $\left(10^{3}\right.$ and $\left.10^{6}\right)$ were presented in Fig. (21) and Fig. (22) for $\left(\mathrm{L}_{b}=0.5, \varphi=0.06\right)$.

While Fig. (23) and Fig. (24) presented this comparison corresponding to the average and local Nusselt numbers. From these figures it is clear that there are no hard effects of the baffle shape in both the streamlines and isotherms configurations and values as like as for average and local Nusselt numbers especially after $\left(\mathrm{Ra}=10^{5}\right)$. Which means that the benefit of manufacturing a less size V-shaped baffle will introduce the same results as that of rectangular shaped baffle which equal to double size of the $\mathrm{V}$-shaped baffle.
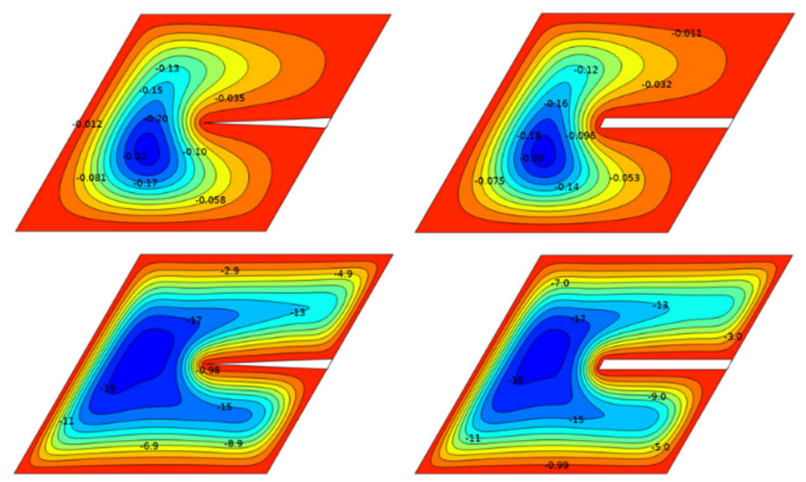

Fig. 21 Comparison of the streamlines for the V-shaped and the rectangular baffles at $\varphi=0.06$ for $\mathrm{Ra}=10^{3}$ (up) and $\mathrm{Ra}=10^{6}$ (down).
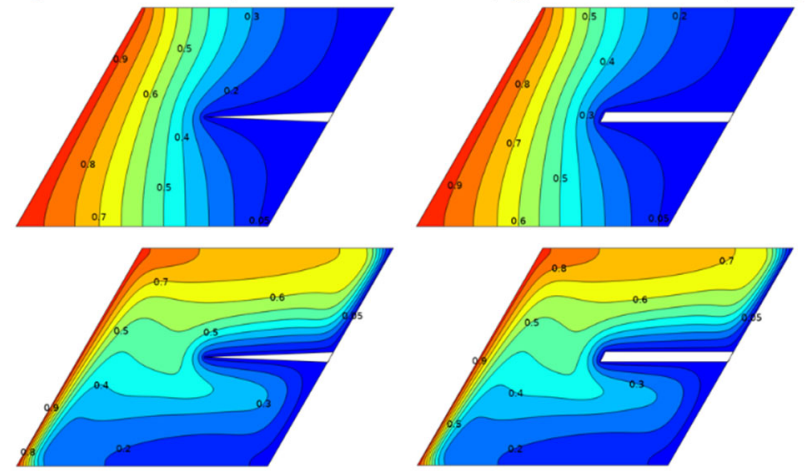

Fig. 22 Comparison of the isotherm lines for the V-shaped and the rectangular baffles at $\varphi=0.06$ for $\mathrm{Ra}=10^{3}$ (up) and $\mathrm{Ra}=10^{6}$ (down).

\section{CONCLUSIONS}

The main findings of the present study are:

1. Attaching a baffle inside a cavity accelerating the convection heat transfer appearance at the same conditions of Rayleigh number and nanofluid concentration comparing to non-baffled cavity.

2. For both non-baffled and baffled cavities, increasing or reducing the Rayleigh number over or below $\left(\mathrm{Ra}=10^{5}\right)$ causing enhancement of the heat transfer by means of Nusselt number increase but this enhancement was more for baffled cavity.

3. At $\left(\mathrm{Ra}=10^{5}\right)$, the Nusselt number nearly equal for non-baffled and baffled cavities. For $(\varphi=0.06)$, the enhancement in the average Nusselt number was $(40 \%)$ over the non-baffled at $\left(\mathrm{Ra}=10^{3}\right)$ and $(10 \%)$ at $\left(\mathrm{Ra}=10^{6}\right)$. Whereas no enhancement over the non-baffled cavity at $\left(\mathrm{Ra}=10^{5}\right)$.

4. The baffle length of $\left(L_{b}=0.75\right)$ and positioned at the middle height of the cavity $\left(H_{b}=0.5\right)$ was the best arrangement, where the enhancement of the locations $\left(H_{b}=0.25\right.$ and $\left.H_{b}=0.75\right)$ is equal which in turn less than the $\left(H_{b}=0.5\right)$ location enhancement by $(4 \%)$.

5. The two baffles were the optimum choice where the best enhancement of the average Nusselt number was founded which was about $(7 \%)$ over the single and the triple baffles cases at $\left(\mathrm{Ra}=10^{5}\right)$ and about $(1 \%$ and $7 \%)$ at $\left(\mathrm{Ra}=10^{6}\right)$. Observing that the enhancement of the average Nusselt number becoming very close for the single and double baffles with Rayleigh number increase.

6. The peak local Nusselt number value at each Rayleigh number occurs at a specified location (height) along the heated wall. These peaks occur at locations of non-higher than $\left(H_{b}=0.25\right)$ for Rayleigh numbers of $\left(10^{5}\right.$ and $\left.10^{6}\right)$ while at Rayleigh number of $\left(10^{3}\right)$ occurs at the top end of the heated wall.

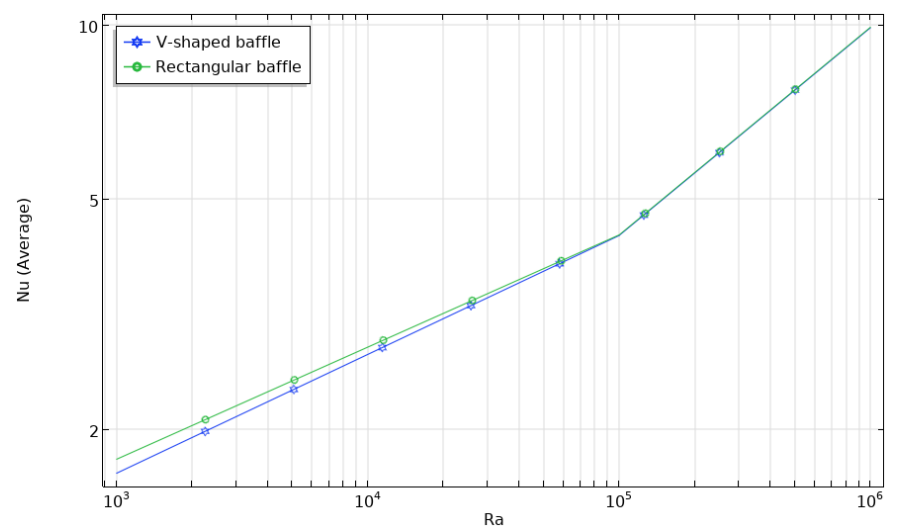

Fig. 23 Comparison of the average $(\mathrm{Nu})$ for the $\mathrm{V}$-shaped and rectangular baffles at $\varphi=0.06$.

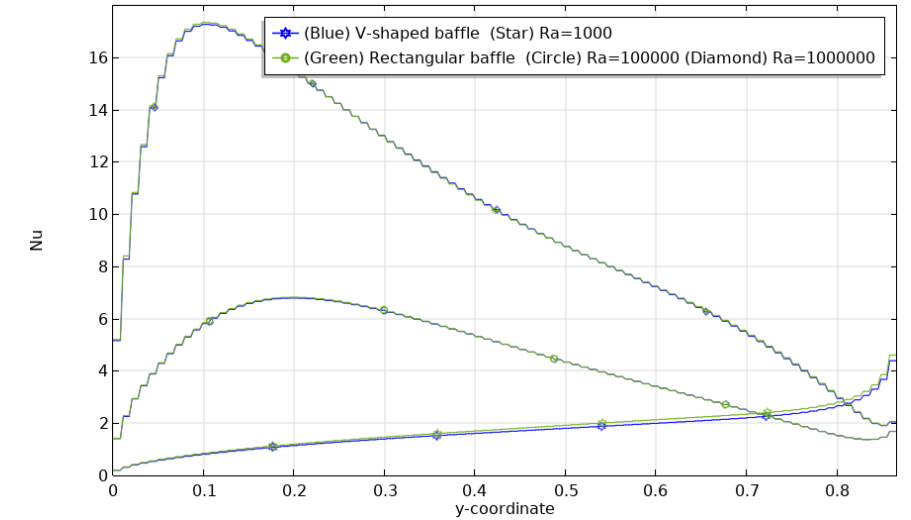

Fig. 24 Comparison of the local $(\mathrm{Nu})$ for the $\mathrm{V}$-shaped and rectangular baffles at $\varphi=0.06$. 
7. The location of the maximum or peak Nusselt number were not affected by the baffle location for the same baffle length. Observing that for length of (0.75) the local Nusselt number has two peak values above the baffle body height (lower peak) and below it (higher peak) for $\left(\mathrm{Ra}=10^{5}\right)$. The peak value for $\left(\mathrm{Ra}=10^{3}\right)$ occurred before the end of the cavity height and has a clear growth comparing to the $(0.25$ and 0.5$)$ lengths.

8. For a specified nanoparticles solid volume fraction, the enhancement in heat transfer over the pure water of $(\mathrm{Cu} /$ water $)$ nanofluid is higher than that of $\left(\mathrm{Al}_{2} \mathrm{O}_{3} /\right.$ water $)$ nanofluid, by a very little rate (less than $1 \%$ ). The enhancement of both the used nanofluids increase with the solid volume fraction increase over the study range $(0.01 \leq \varphi \leq 0.06)$.

\section{NOMENCLATURE}

$C_{p} \quad$ specific heat at constant pressure $(\mathrm{J} / \mathrm{Kg} \cdot \mathrm{K})$

$g \quad$ acceleration duo to gravity $\left(\mathrm{m} / \mathrm{s}^{2}\right)$

$h_{b} \quad$ baffle position (m)

$H_{b} \quad$ dimensionless baffle position

$K \quad$ thermal conductivity (W/m.K)

$L \quad$ cavity side wall length (m)

$l_{b} \quad$ baffle length $(\mathrm{m})$

$L_{b} \quad$ dimensionless baffle length

$\mathrm{Nu} \quad$ local Nusselt number

$P \quad$ dimensionless pressure

Pr Prandtl number

$\mathrm{Ra} \quad$ Rayleigh number

$T \quad$ temperature

$U \quad$ dimensionless velocity component in x-direction

$V \quad$ dimensionless velocity component in y-direction

$w_{b} \quad$ baffle base width

$W_{b} \quad$ dimensionless baffle base width

$X \quad$ dimensionless coordinate in horizontal direction

$Y \quad$ dimensionless coordinate in vertical direction

Greek Symbols

$\alpha \quad$ thermal diffusivity $\left(\mathrm{m}^{2} / \mathrm{s}\right)$

$\beta \quad$ coefficient of thermal expansion $\left(\mathrm{K}^{-1}\right)$

$\theta \quad$ dimensionless temperature

$\mu \quad$ dynamic viscosity $(\mathrm{Kg} / \mathrm{m} . \mathrm{s})$

$\rho \quad$ density $\left(\mathrm{kg} / \mathrm{m}^{3}\right)$

$v \quad$ kinematic viscosity $\left(\mathrm{m}^{2} / \mathrm{s}\right)$

$\varphi \quad$ nanoparticles solid volume fraction

$\Psi \quad$ dimensionless stream function

\section{Subscripts}

avg average

c cold

eff effective

$f \quad$ fluid

$h \quad$ hot

nf nanofluid

$p \quad$ particle

\section{REFERENCES}

Abu-Nada, E., Oztop, H.F., 2009, "Effects of inclination angle on natural convection in enclosures filled with $\mathrm{Cu}$-water nanofluid", International Journal of Heat and Fluid Flow. https://doi.org/10.1016/j.ijheatfluidflow.2009.02.001

Ahmadi, M.H., Mirlohi, A., Nazari, M.A., Ghasempour, R., 2018, “A review of thermal conductivity of various nanofluids", Journal of Molecular Liquids, 265, 181-188.

https://doi.org/10.1016/j.molliq.2018.05.124
Ambarita, H., Kishinami, K., Daimaruya, M., T. Saitoh, T., Takahashi, H., Suzuki, J., 2006, "Laminar natural convection heat transfer in an air filled square cavity with two insulated baffles attached to its horizontal walls", Thermal science and engineering, 14 (3), 35-46.

https://doi.org/10.11368/tse.14.35

Armaghani, T., Kasaeipoor, A., Alavi, N., Rashidi, M.M., 2016, "Numerical investigation of water-alumina nanofluid natural convection heat transfer and entropy generation in a baffled L-shaped cavity", Journal of Molecular Liquids, 223, 243-251.

https://doi.org/10.1016/j.molliq.2016.07.103

Asl, A.K., Hossainpour, S., Rashidi, M.M., Sheremet, M.A., Yang, Z., 2019, "Comprehensive investigation of solid and porous fins influence on natural convection in an inclined rectangular enclosure", Int. J. Heat Mass Transf., 133, 729-744.

https://doi.org/10.1016/j.ijheatmasstransfer.2018.12.156

Baïri, A., Pernia, E.Z., García de María, J.-M., 2014, “A review on natural convection in enclosures for engineering applications. The particular case of the parallelogrammic diode cavity", Applied Thermal Engineering, 63, 304-322.

https://doi.org/10.1016/j.applthermaleng.2013.10.065

Bendaraa, A., Charafi, M.M., Hasnaoui, A., 2019, "Numerical study of natural convection in a differentially heated square cavity filled with nanofluid in the presence of fins attached to walls in different locations", Physics Fluids, 31, 052003. https://doi.org/10.1063/1.5091709

Ben-Nakhi, A., Chamkha, A.J., 2006, "Effect of length and inclination of a thin fin on natural convection in a square enclosure", Numerical Heat Transfer, Part A: Applications: An International Journal of Computation and Methodology, 50 (4), 381-399.

https://doi.org/10.1080/10407780600619907

Bilgen, E., 2005, "Natural convection in cavities with a thin fin on the hot wall", International Journal of Heat and Mass Transfer, 48, 34933505.

https://doi.org/10.1016/j.ijheatmasstransfer.2005.03.016

Chahrazed, B., Samir, R., 2012, "Simulation of heat transfer in a square cavity with two fins attached to the hot wall", Energy Procedia. 18, 12991306.

https://doi.org/10.1016/j.egypro.2012.05.147

Chen, H.T., Lin, M.C., Chang, J.R., 2018, "Numerical and experimental studies of natural convection in a heated cavity with a horizontal fin on a hot sidewall", International Journal of Heat and Mass Transfer, 124, 1217-1229.

https://doi.org/10.1016/j.ijheatmasstransfer.2018.04.046

Devendiran, D.K., Amirtham, V.A., 2016, "A review on preparation, characterization, properties and applications of nanofluids", Renewable and Sustainable Energy Reviews, 60, 21-40.

https://doi.org/10.1016/j.rser.2016.01.055

Du, R., Gokulavanib, P., Muthtamilselvan, M., Al-Amri,F., Abdalla, B., 2020, "Influence of the Lorentz force on the ventilation cavity having a centrally placed heated baffle filled with the $\mathrm{Cu}-\mathrm{Al}_{2} \mathrm{O}_{3}-\mathrm{H} 2 \mathrm{O}$ hybrid nanofluid", International Communications in Heat and Mass Transfer, 116, 104676.

https://doi.org/10.1016/j.icheatmasstransfer.2020.104676

Elatar, A., Teamah, M.A., Hassab, M.A., 2016, "Numerical study of laminar natural convection inside square enclosure with single horizontal fin”, Int. J. Thermal Sciences, 99, 41-51. 
https://doi.org/10.1016/j.ijthermalsci.2015.08.003

Emad, D.A., Qusay, R.A., Hameed K.H., Ammar, A., Mustafa, M.G., Salwan, O.W. K., Farooq, H.A., 2021, "Natural convection in sinusoidal-corrugted enclosure utitiing silver/water nanofluid with different shapes of concentric inner cylinders", Frontiers in Heat and Mass Transfer, 17 (19).

http://dx.doi.org/10.5098/hmt.17.19

Ghasemi, B., Aminossadati, S.M., 2009, "Natural convection heat transfer in an inclined enclosure filled with a water- $\mathrm{CuO}$ nanofluid", Numerical Heat Transfer Part A: Applications: An International Journal of Computation and Methodology, 55 (8), 807-823. https://doi.org/10.1080/10407780902864623

Giwa, S.O., Sharifpur, M., Ahmadi, M.H., Meyer, J.P., 2020, “A review of magnetic field influence on natural convection heat transfer performance of nanofluids in square cavities", Journal of Thermal Analysis and Calorimetry.

https://doi.org/10.1007/s10973-020-09832-3

Guiet, J., Reggio, M., Vasseur, P., 2012, "Natural convection of nanofluids in a square enclosure with a protruding heater", Advances in Mechanical Engineering, 167296.

https://doi.org/10.1155/2012/167296

Habibzadeh, A., Sayehvand, H., Mekanik, A., 2011, "Numerical study of natural convection in a partitioned square cavity filled with nanofluid", International Journal of Chemical Engineering and Applications, 2, 269274.

https://doi.org/10.7763/IJCEA.2011.V2.114

Ho, C.J., Chen, M.W., Li, Z.W., 2008, "Numerical simulation of natural convection of nanofluid in a square enclosure: Effects due to uncertainties of viscosity and thermal conductivity", International Journal of Heat and Mass Transfer, 51, 4506-4516. https://doi.org/10.1016/j.ijheatmasstransfer.2007.12.019

Hussein, A.K., AWAD, M.M., Kolsi, L., Fathinia, F., Adegun, I.K., 2014, "A comprehensive review of transient natural convection flow in enclosures", Journal of Basic and Applied Scientific Research, 4 (11), $17-27$.

Hussein, A.K., Ghodbane, M., Said, Z., Ward, R.S., 2020, "The effect of the baffle length on the natural convection in an enclosure filled with different nanofluids", Journal of Thermal Analysis and Calorimetry. https://doi.org/10.1007/s10973-020-10300-1

Hussein, A.K., Mustafa, A.W., 2017, "Natural convection in fully open parallelogramic cavity filled with $\mathrm{Cu}$-water nanofluid and heated locally from its bottom wall", Thermal Science and Engineering Progress, 1, 6677.

https://doi.org/10.1016/j.tsep.2017.03.002

Keramata, F., Dehghana, P., Mofarahia, M., Lee, C., 2020, "Numerical analysis of natural convection of alumina-water nanofluid in $\mathrm{H}$-shaped enclosure with a V-shaped baffle", Journal of the Taiwan Institute of Chemical Engineers, 111, 63-72.

https://doi.org/10.1016/i.jtice.2020.04.006

Lai, F.H., Y. T. Yang, Y.T., 2011, "Lattice Boltzmann simulation of natural convection heat transfer of $\mathrm{Al}_{2} \mathrm{O}_{3}$ /water nanofluids in a square enclosure", International Journal of Thermal Sciences, 50, 1930-1941. https://doi.org/10.1016/j.ijthermalsci.2011.04.015
Ma, Y., Mohebbi, R., Rashidi, M.M., Yang, Z., Sheremet, M.A., 2019 "Numerical study of MHD nanofluid natural convection in a baffled Ushaped enclosure", International Journal of Heat and Mass Transfer, 130, 123-134.

https://doi.org/10.1016/j.ijheatmasstransfer.2018.10.072

Mahmoodi, M., 2011, "Numerical simulation of free convection of nanofluid in a square cavity with an inside heater", International Journal of Thermal Science, 50, 2161-2175. https://doi.org/10.1016/j.ijthermalsci.2011.05.008

Mahmoudi, A.H., Shahi, M., Raouf, A.H., Ghasemian, A., 2010, "Numerical study of natural convection cooling of horizontal heat source mounted in a square cavity filled with nanofluid", International Communications in Heat and Mass Transfer, 37, 1135-1141. https://doi.org/10.1016/j.icheatmasstransfer.2010.06.005

Majdi, H.S., Abdulkadhim, A., Abed, A.M., 2019, "Numerical investigation of natural convection heat transfer in a parallelogramic enclosure having an inner circular cylinder using liquid nanofluid", Frontiers in Heat and Mass Transfer, 12 (2).

https://doi.org/10.5098/hmt.12.2

Mobedi, M., 2008, "Conjugate natural convection in a square cavity with finite thickness horizontal walls", International Communications in Heat and Mass Transfer, 35, 503-513.

https://doi.org/10.1016/j.icheatmasstransfer.2007.09.004

Mahmud, H.A., Rawand E.J., 2020, "Natural convection in a square enclosure with different opening and involves two cylinders: A numerical approach", 15 (27).

http://dx.doi.org/10.5098/hmt.15.27

Murshed, S.M.S., Sharifpur, M., Giwa, S., Meyer, J.P., 2020, "Experimental research and development on the natural convection of suspensions of nanoparticles-A comprehensive review", nanomaterials, 10,1855 .

https://doi.org/10.3390/nano10091855

Naoufal, Y., Zaydan, M., Rachid, S., 2015, "Numerical study of natural convection in a square cavity with partitions utilizing $\mathrm{Cu}$-water nanofluid", International Journal of Innovative Research in Science, Engineering and Technology, 4 (11), 10354-10367.

https://doi.org/10.15680/IJIRSET.2015.0411006

Nardini, G., Paroncini, M., Vitali, R., 2015, "Natural convection in a square cavity with two baffles on the vertical walls: experimental and numerical investigation", International Journal of Mechanics, 9, 120127.

Nia, S.N., Rabiei, F., Rashidi, M.M., Kwang, T.M., 2020, "Lattice Boltzmann simulation of natural convection heat transfer of a nanofluid in a L-shape enclosure with a baffle", Results in Physics, 19, 103413. https://doi.org/10.1016/j.rinp.2020.103413

Olanrewaju, M.O., Samuel, I.A., Olawale, S.I., 2021, "Numerical simulation of natural convection in rectangular cavities with different aspect ratios", Frontiers in Heat and Mass Transfer, 17-11. http://dx.doi.org/10.5098/hmt.17.11

Oztop, H., Bilgen, E., 2006, "Natural convection in differentially heated and partially divided square cavities with internal heat generation", international journal of heat and fluid flow, 27 (3), 466-475. https://doi.org/10.1016/j.ijheatfluidflow.2005.11.003 
Öztop, H.F., Estellé, P., Yan, W.M., Al-Salem, K., Orfi, J., Mahian, O., 2014, "A brief review of natural convection in enclosures under localized heating with and without nanofluids", International Communications in Heat and Mass Transfer. https://doi.org/10.1016/j.icheatmasstransfer.2014.11.001

Oztop, H.F., Mobedi, M., Abu-Nada, E., Pop, I., 2012, "A heatline analysis of natural convection in a square inclined enclosure filled with a $\mathrm{CuO}$ nanofluid under non-uniform wall heating condition", International Journal of Heat and Mass Transfer, 55, 5076-5086. https://doi.org/10.1016/j.ijheatmasstransfer.2012.05.007

Öztuna, S., Kahveci, K., 2013, "Natural convection heat transfer of nanofluids in a partially divided enclosure", Journal of Thermal Science and Technology, 33(1), 139-154.

Qi, C., Wang, G., Yang, L., Wan, Y., Rao, Z., 2017, “Two-phase lattice Boltzmann simulation of the effects of base fluid and nanoparticle size on natural convection heat transfer of nanofluid", International Journal of Heat and Mass Transfer, 105, 664-672.

https://doi.org/10.1016/j.ijheatmasstransfer.2016.10.043

Raisi, A., 2018, "The effect of conductive baffles on natural convection in a power-law fluid-filled square cavity", Journal of the Brazilian Society of Mechanical Sciences and Engineering. https://doi.org/10.1007/s40430-018-0969-z

Rostami, S., Aghakhani, S., Pordanjani, A.H., Afrand, M., Cheraghian, G., Oztop, H.F., Shadloo, M.S., 2020, "A review on the control parameters of natural convection in different shaped cavities with and without nanofluid", Processes.

https://doi.org/10.3390/pr8091011

Saeid, N.H., 2018, "Natural convection in a square cavity with discrete heating at the bottom with different fin shapes", Heat Transfer Engineering, 39 (2), 154-161. https://doi.org/10.1080/01457632.2017.1288053

Safiei, W., Rahman, M.M., Kulkarni, R., Ariffin, M.N., Abd Malek, Z.A., 2020, "Thermal conductivity and dynamic viscosity of nanofluids: A review", Journal of Advanced Research in Fluid Mechanics and Thermal Sciences, 74 (2), 66-84. https://doi.org/10.37934/arfmts.74.2.6684

Sayehvand, H., Habibzadeh, A., Mekanik, A., 2012, "CFD analysis of natural convection heat transfer in a square cavity with partitions utilizing $\mathrm{Al}_{2} \mathrm{O}_{3}$ nanofluid", International Journal of Nano Dimension, 2(3), 191-200.

https://doi.org/10.7508/IJND.2011.03.007
Selimefendigil, F., 2017, "Natural Convection in a Trapezoidal Cavity with an Inner Conductive Object of Different Shapes and Filled with Nanofluids of Different Nanoparticle Shapes", Iran J Sci Technol Trans Mech Eng.

https://doi.org/10.1007/s40997-017-0083-3

Selimefendigil, F., Öztop, H.F., 2016, "Conjugate natural convection in a cavity with a conductive partition and filled with different nanofluids on different sides of the partition", Journal of Molecular Liquids, 67-77. https://doi.org/10.1016/j.molliq.2015.12.102

Sheikhzadeh, G.A., Pirmohammadi, M., Ghassemi, M., 2007, "A numerical study of natural convection in a cavity with two fins attached to its vertical walls", ASME International Mechanical Engineering Congress and Exposition. https://doi.org/10.1115/IMECE2007-43210

Shi, X., Khodadadi, J.M., 2003, "Laminar Natural Convection Heat Transfer in a Differentially Heated Square Cavity Due to a Thin Fin on the Hot Wall", J. of Heat Transfer, 125, 624 - 634.

https://doi.org/10.1115/1.1571847

Siavashi, M., Yousofvand, R., Rezanejad, S., 2018, "Nanofluid and porous fins effect on natural convection and entropy generation of flow inside a cavity", Advanced Powder Technology, 29 (1), 142-156. https://doi.org/10.1016/j.apt.2017.10.021

Sidika, N.A.C., Jamil, M.M., Japar, W.M.A.A., Adamu, I.M., 2017, “A review on preparation methods, stability and applications of hybrid nanofluids", Renewable and Sustainable Energy Reviews, 80, 11121122.

https://doi.org/10.1016/j.rser.2017.05.221

Tasnim, S.H., Collins, M.R., 2004, "Numerical analysis of heat transfer in a square cavity with a baffle on the hot wall", International Communications in Heat and Mass Transfer, 31 (5), 639-650. https://doi.org/10.1016/S0735-1933(04)00051-X

Tighchi, H.A., Sobhani, M., Esfahani, J.A., 2018, "Effect of volumetric radiation on natural convection in a cavity with a horizontal fin using the lattice Boltzmann method", The European Physical Journal plus, 133 (1) 8. https://doi.org/10.1140/epip/i2018-11835-1

Torabi, M., Keyhani, A., Peterson, G.P., 2017, "A comprehensive investigation of natural convection inside a partially differentially heated cavity with a thin fin using two-set lattice Boltzmann distribution functions", International Journal of Heat and Mass Transfer, 115, 264277.

https://doi.org/10.1016/j.ijheatmasstransfer.2017.07.042 